\title{
Atmospheric turbulence triggers pronounced diel pattern in karst carbonate geochemistry
}

M. Roland ${ }^{1}$, P. Serrano-Ortiz ${ }^{2,3}$ A. S. Kowalski ${ }^{3,4}$ Y. Goddéris ${ }^{5}$ E. P. Sánchez-Cañete ${ }^{2,3}$ P. Ciais ${ }^{6}$ F. Domingo ${ }^{2}$ S. Cuezva ${ }^{7}$, S. Sanchez-Moral ${ }^{8}$, B. Longdoz ${ }^{9}$, D. Yakir ${ }^{10}$, R. Van Grieken ${ }^{11}$, J. Schott ${ }^{5}$, C. Cardell ${ }^{12}$, and I. A. Janssens ${ }^{1}$

${ }^{1}$ Department of Biology, University of Antwerp, Universiteitsplein 1, 2610 Wilrijk, Belgium

${ }^{2}$ Estación Experimental de Zonas Áridas, Consejo Superior de Investigaciones Científicas (CSIC), Carretera de Sacramento s/n, 04120 Almería, Spain

${ }^{3}$ Grupo de Física de la Atmósfera, Centro Andaluz de Medio Ambiente (CEAMA), Avenida del Mediterráneo s/n, 18006 Granada, Spain

${ }^{4}$ Departamento de Física Aplicada, Universidad de Granada, Avenida Fuentenueva s/n, 18071 Granada, Spain

${ }^{5}$ Geosciences Environnement Toulouse (GET), Observatoire Midi-Pyrénées, CNRS, Avenue Edouard Belin 14, 31400 Toulouse, France

${ }^{6}$ Laboratoire des Sciences du Climat et de l'Environnement (LSCE), CEA CNRS UVSQ, Orme des Merisiers s/n, 91191 Gif-sur-Yvette, France

${ }^{7}$ Departamento de Ciencias de la Tierra y del Medio Ambiente, Universidad de Alicante, Campus de Sant Vicent del Raspeig, 03080 Alicante, Spain

${ }^{8}$ Departamento de Geología, Museo Nacional Ciencias Naturales (MNCN-CSIC), José Gutiérrez Abascal 2, 28006 Madrid, Spain

${ }^{9}$ Ecologie et Ecophysiologie Forestières (EEF), UMR1137, INRA, 54280 Champenoux et Université de Lorraine, 54500 Vandoeuvre Les Nancy, France

${ }^{10}$ Environmental Sciences and Energy Research, Weizmann Institute of Science, 76100 Rehovot, Israel

${ }^{11}$ Department of Chemistry, University of Antwerp, Universiteitsplein 1, 2610 Wilrijk, Belgium

${ }^{12}$ Departamento Mineralogía y Petrología, Universidad de Granada, Avenida Fuentenueva s/n, 18071 Granada, Spain

Correspondence to: M. Roland (marilyn.roland@ua.ac.be)

Received: 27 November 2012 - Published in Biogeosciences Discuss.: 28 January 2013

Revised: 21 May 2013 - Accepted: 6 June 2013 - Published: 24 July 2013

\begin{abstract}
CO}_{2}$ exchange between terrestrial ecosystems and the atmosphere is key to understanding the feedbacks between climate change and the land surface. In regions with carbonaceous parent material, $\mathrm{CO}_{2}$ exchange patterns occur that cannot be explained by biological processes, such as disproportionate outgassing during the daytime or nighttime $\mathrm{CO}_{2}$ uptake during periods when all vegetation is senescent. Neither of these phenomena can be attributed to carbonate weathering reactions, since their $\mathrm{CO}_{2}$ exchange rates are too small. Soil ventilation induced by high atmospheric turbulence is found to explain atypical $\mathrm{CO}_{2}$ exchange between carbonaceous systems and the atmosphere. However, by strongly altering subsurface $\mathrm{CO}_{2}$ concentrations, ventila-
\end{abstract}

tion can be expected to influence carbonate weathering rates. By imposing ventilation-driven $\mathrm{CO}_{2}$ outgassing in a carbonate weathering model, we show here that carbonate geochemistry is accelerated and does play a surprisingly large role in the observed $\mathrm{CO}_{2}$ exchange pattern of a semi-arid ecosystem. We found that by rapidly depleting soil $\mathrm{CO}_{2}$ during the daytime, ventilation disturbs soil carbonate equilibria and therefore strongly magnifies daytime carbonate precipitation and associated $\mathrm{CO}_{2}$ production. At night, ventilation ceases and the depleted $\mathrm{CO}_{2}$ concentrations increase steadily. Dissolution of carbonate is now enhanced, which consumes $\mathrm{CO}_{2}$ and largely compensates for the enhanced daytime carbonate precipitation. This is why only a relatively 
small effect on global carbonate weathering rates is to be expected. On the short term, however, ventilation has a drastic effect on synoptic carbonate weathering rates, resulting in a pronounced diel pattern that exacerbates the non-biological behavior of soil-atmosphere $\mathrm{CO}_{2}$ exchanges in dry regions with carbonate soils.

\section{Introduction}

The net carbon balance of ecosystems has become a key focus in the study of the global carbon cycle. The assessment of net ecosystem $\mathrm{CO}_{2}$ fluxes on different scales of time and space is enabled through eddy covariance measurements that are being performed on "flux towers" around the globe (Baldocchi et al., 2001). Usually these net $\mathrm{CO}_{2}$ exchanges with the atmosphere are interpreted as the sum of the photosynthetic and respiratory components, while little is known about the role of geological carbon cycling in the soilatmosphere $\mathrm{CO}_{2}$ exchange. Recent studies in regions with carbonate bedrock, however, have reported ecosystem $\mathrm{CO}_{2}$ flux patterns that are not easily explained only by photosynthesis and respiration (Schlesinger et al., 2009; Serrano-Ortiz et al., 2010; Stone 2008; Wohlfahrt et al., 2008; Xie et al., 2009). Daytime $\mathrm{CO}_{2}$ emissions several orders of magnitude larger than what could be expected from biological principles (Emmerich 2003; Kowalski et al., 2008; Mielnick et al., 2005), and nighttime $\mathrm{CO}_{2}$ uptake during periods when plants are dormant (Hastings et al., 2005; Kowalski et al., 2008) imply that other processes are playing a role in this exchange. Weathering of carbonates (including both dissolution and precipitation) was suspected to contribute to the observed fluxes (Emmerich 2003; Kowalski et al., 2008; Mielnick et al., 2005; Schlesinger et al., 2009; Serrano-Ortiz et al., 2010; Stone, 2008). Given that carbonate systems cover more than $10 \%$ of the world's land surface (Durr et al., 2005), the hypothesized important contribution of carbonate weathering to the $\mathrm{CO}_{2}$ flux measurements needs to be tested.

Under steady state conditions, $\mathrm{CO}_{2}$ is connected to soil carbonates via the following summarized carbonate weathering reaction (Berner et al., 1983; Kaufmann and Dreybrodt, 2007):

$$
\mathrm{CACO}_{3(\mathrm{~s})}+\mathrm{CO}_{2(\mathrm{aq})}+\mathrm{H}_{2} \mathrm{O}_{(\mathrm{aq})} \leftrightarrows \mathrm{Ca}^{2+}{ }_{(\mathrm{aq})}+2 \mathrm{HCO}_{3}^{-}(\mathrm{aq})
$$

In the absence of external drivers, this system approaches equilibrium closely within minutes (Dreybrodt et al., 1996). In the real world, fluctuations in $\mathrm{CO}_{2}$ production, soil water content and atmospheric conditions maintain carbonate reactions permanently in disequilibrium. The reactions are also affected by changes in soil $\mathrm{pH}$ induced by atmospheric deposition and drainage (downward leaching of $\mathrm{Ca}^{2+}$ and DIC; dissolved inorganic carbon) (Suchet and Probst, 1995). The most important driver is probably the soil moisture content as it determines how much DIC and $\mathrm{Ca}^{2+}$ can be in solution. In dryer regions or periods, daytime evaporative water losses induce oversaturation of DIC and thus precipitation of calcium carbonate and associated production of $\mathrm{CO}_{2}$. In dry conditions, these daytime water losses are often compensated during the night, at least partly, by water vapor condensation or adsorption (Kosmas et al., 2001; Verhoef et al., 2006), causing undersaturation of DIC that leads to the reverse reactions: dissolution of carbonates and $\mathrm{CO}_{2}$ uptake. If this dissolution exceeds $\mathrm{CO}_{2}$ production within the soil, then nighttime $\mathrm{CO}_{2}$ uptake from the atmosphere could occur, as occasionally reported in literature (Hastings et al., 2005; Kowalski et al., 2008). The diel pattern of $\mathrm{CO}_{2}$ uptake and release due to carbonate geochemical reactions is thus opposite in sign compared to the biological pattern. Note that ambiguity exists among the terms "source" and "sink" when considering the $\mathrm{CO}_{2}$ exchange between carbonate rocks and the atmosphere on one hand, and carbon sequestration in carbonate rocks on the other hand (Eshel et al., 2007). Here we consider carbonate dissolution a sink as it holds $\mathrm{CO}_{2}$ uptake by the ecosystem and carbonate precipitation a source as it causes $\mathrm{CO}_{2}$ emission to the atmosphere. In terms of the soil carbon pool, however, carbonate precipitation is considered a sink as it implies carbon sequestration and carbonate dissolution is considered a source as implies a loss from the soil carbon pool.

Whereas $\mathrm{CO}_{2}$ transport along the soil profile is determined primarily by diffusion, $\mathrm{CO}_{2}$ movement in permeable, dry and fractured sub-soil and its release at the soil surface are strongly influenced by non-diffusional mechanisms, such as pressure gradients, gusts and turbulence (Rey et al., 2012), which from now on we call ventilation. The term refers to different processes causing mass transfer of soil and cave air to the atmosphere and vice versa, such as pressure pumping, deep penetration of eddies or the Venturi effect. Ventilation occurs in all porous media, such as non-saturated soils and karst systems, when pores are connected (open porosity) and not blocked by water (Cuezva et al., 2011). Takle et al. (2004) found that pressure fluctuations causing mass transfer through the soil penetrated into a dry soil up to $50 \mathrm{~cm}$ with little attenuation. The airflow induced by pressure pumping is controlled by the degree of permeability of the medium and the direction and magnitude of the pressure gradient (Massman et al., 1995; Takle et al., 2003). Turbulent wind can instigate ventilation when large eddies penetrate deep into the soil and result in mixing of soil and atmospheric air. This is further enhanced when the surface is heated and the air at the soil surface becomes buoyant and unstable, enabling better mixing. It is important to distinguish between ventilation, which is the physical air mass transfer process, and the $\mathrm{CO}_{2}$ outgassing as a consequence of ventilation, which depends on the concentration of $\mathrm{CO}_{2}$ present in the soil.

By pumping in $\mathrm{CO}_{2}$-poor air, and pumping out $\mathrm{CO}_{2}$-rich air, ventilation drastically reduces the belowground $\mathrm{CO}_{2}$ concentrations in soil pores and caves (Cuezva et al., 2011; Kowalski et al., 2008). These rapid changes in underground 
$\mathrm{CO}_{2}$ concentrations induce a strong carbonate disequilibrium and can thus be expected to interact with carbonate weathering rates. In this paper we use a modeling approach to determine to what degree the occurrence of ventilation affects carbonate geochemistry.

\section{Materials and methods}

\subsection{Study area}

Data were taken from a study area in the southeast of Spain (province of Almería), El Llano de los Juanes, where ventilation has been reported (Serrano-Ortiz et al., 2010; SanchezCañete et al., 2011). It is located in the Sierra de Gádor, a mountain range which reaches $2246 \mathrm{~m}$ above sea level (Li et al., 2007, 2008). The Sierra consists of an up to $1000 \mathrm{~m}$ thick series of Triassic carbonate rocks (limestone and dolomite) that are highly permeable and fractured.

The study site El Llano de los Juanes, with an elevation of about $1660 \mathrm{~m}$ above sea level is a relatively flat shrubland area corresponding to a well-developed karstic plateau (Serrano-Ortiz et al., 2007). The carbonate rocks here are mainly dark limestone, with $98 \%$ calcite (X-ray diffraction analysis) (Were et al., 2010). The site is characterized by a semiarid montane Mediterranean climate, with a mean annual temperature of $12{ }^{\circ} \mathrm{C}$ and mean annual precipitation of ca. $475 \mathrm{~mm}$, falling mostly during autumn and winter, and by a very dry season in summer (Serrano-Ortiz et al., 2007; Kowalski et al., 2008). Thickness of the soil overlaying the bedrock ranges from 0 to $0.5 \mathrm{~m}$. The vegetation, so-called "Macchia" or "Matorral", at this study site is sparse and only around $0.5 \mathrm{~m}$ in height, but nonetheless bio-diverse. More information on the study area can be found in the Supplement (A1.2 Site description and geological context)

\subsection{Model description}

Chemical weathering of carbonates was simulated using an updated version of the WITCH box-model (Goddéris et al., 2010; Goddéris et al., 2006; Roelandt et al., 2010). WITCH simulates the time evolution of the chemical composition of belowground waters and air, as well as their vertical fluxes. For each water reservoir, corresponding to a given soil and weathering profile layer, the mass balance is solved for every time step. The outputs of these budget equations - i.e., carbon content, dissolved calcium, and total alkalinity in each modeled layer - are injected at each time step into the speciation module that calculates the complete carbonate speciation accounting for the environmental conditions (such as the fluctuating temperature and water volumetric content). A detailed description of the WITCH model can be found in the Supplement (A1.1 Model description.)

The gas transport mechanism in the standard version of WITCH is diffusion, but here we also needed to prescribe a $\mathrm{CO}_{2}$ efflux as a result of ventilative outgassing. As several

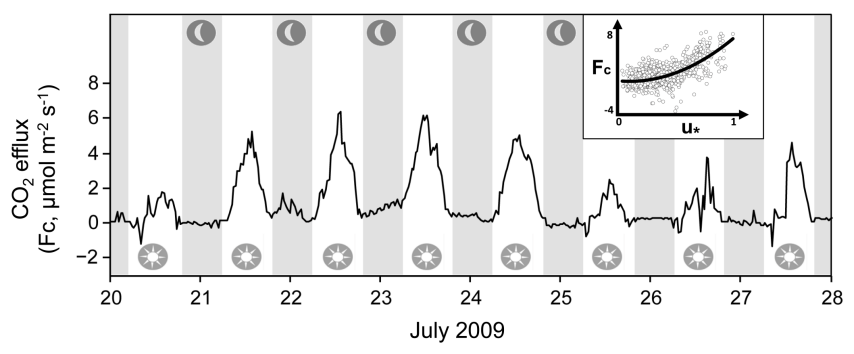

Fig. 1. Measured $\mathrm{CO}_{2}$ efflux from an ecosystem on carbonate (dry season). Example of a period in which atmospheric turbulence induces $\mathrm{CO}_{2}$ outgassing events during the daytime in a dry Spanish "Matorral" vegetation growing on karst. The inset shows that outgassing increases exponentially with $u_{*}$, a measure for atmospheric turbulence. Because of the drought during this time of year, plants are in a dormant stage and the observed daytime $\mathrm{CO}_{2}$ effluxes have to be attributed to ventilation. In 2009, ventilation was observed here daily from the end of 24 June until the beginning of 7 September. The figure shows the clearest case of ventilation, peak daytime effluxes averaged around $2 \mu \mathrm{mol} \mathrm{m}^{-2} \mathrm{~s}^{-1}$ (ranging between $0.5-6.4 \mu \mathrm{mol} \mathrm{m}{ }^{-2} \mathrm{~s}^{-1}$ ) in 2009.

authors showed a strong correlation between the amount of atmospheric turbulence and ventilation measured at this site, we set up an equation using the friction velocity $u_{*}$ (see Fig. 1 inset, and also Kowalski et al., 2008; Sanchez-Cañete et al., 2011; Serrano-Ortiz et al., 2010).

$u_{*}\left(\mathrm{~m} \mathrm{~s}^{-1}\right)$ is related to surface shear stress, responsible for generating turbulence, and therefore a proxy for atmospheric turbulence. Other parameters included in this equation are the soil water content, which determines the degree of coupling between the underground system and the atmosphere, and the belowground $\mathrm{CO}_{2}$ concentrations. The $\mathrm{CO}_{2}$ efflux $\left(\mu \mathrm{mol} \mathrm{m}{ }^{-2} \mathrm{~s}^{-1}\right)$ due to ventilation $\left(F_{\text {Vent }}\right)$ was therefore prescribed as

$F_{\text {Vent }}=k \cdot u_{*} \cdot \Delta\left[\mathrm{CO}_{2}\right] \cdot I_{\mathrm{r}} \cdot u_{* \theta}$,

where $\Delta\left[\mathrm{CO}_{2}\right]$ is the difference in $\mathrm{CO}_{2}$ concentration between the layer where ventilation occurs and the atmosphere. Ventilation ceases if soil $\mathrm{CO}_{2}$ concentrations are depleted. $I_{\mathrm{r}}$ is the solar radiation deduced from measurements of PPFD (photosynthetic photon flux density). It accounts for surface heating, which induces mass transport through convective flows. $k$ is a constant accounting for the site specific texture of the belowground system. The more fractionated it is and the more caves occur in it, the higher the value of $k$. Ventilation is promoted in highly fractionated karst systems such as our study area. $u_{*}\left(\mathrm{~m} \mathrm{~s}^{-1}\right)$ is a threshold depending on the ratio between the amplitude of atmospheric turbulence and the amount of water in the soil $\left(\frac{u_{*}}{\mathrm{VWC}}\right)$, and on the maximum water content for enabling ventilation $\left(\mathrm{VWC}_{\mathrm{Vmax}}\right)$. In these simulations we allowed ventilation only when $u_{* \theta}>2$ (VWC expressed in $\mathrm{m}^{3} \mathrm{~m}^{-3}$ and $u_{*}$ in $\mathrm{m} \mathrm{s}^{-1}$ ) and $\mathrm{VWC}_{\mathrm{Vmax}} \leq 0.1$. Estimations for $k$ and $u_{* \theta}$ are site specific. By adjusting the parameters in this 
equation to meet the observed fluxes, we achieved a realistic estimate for the amount of $\mathrm{CO}_{2}$ that is extracted from the soil by ventilation.

At this point we emphasize that the ventilation equation cannot be fully validated and site-specific parameters should be evaluated before applying them to other study areas. Besides the techniques for such validation not being in reach, it was not found to be of critical importance for the purpose of this study, which was to test to what degree ventilation affects geochemical fluxes, rather than quantifying ventilative outgassing itself. The latter requires detailed insight in the three-dimensional structure of the karst system to estimate macropore interconnectivity and the presence of caves and cracks that serve as preferential $\mathrm{CO}_{2}$ outflows.

We designed the model simulations to accord with the conditions of the Mediterranean study area (see Supplement A1.2 Site description and geological context). The weathering profile was prescribed as a ten-layer structure with a total thickness of $100 \mathrm{~m}$, the two upper layers having soil properties (porosity $0.59 \mathrm{~m}^{3} \mathrm{~m}^{-3}$ - measured on site - and thickness $15 \mathrm{~cm}$ each) and the others layers having bedrock properties (porosity of $0.03 \mathrm{~m}^{3} \mathrm{~m}^{-3}$ - measured on site - and thickness resp. $4 \mathrm{~m}, 4 \mathrm{~m}, 4 \mathrm{~m}, 10 \mathrm{~m}, 10 \mathrm{~m}, 10 \mathrm{~m}, 10 \mathrm{~m}$ and $47.7 \mathrm{~m}$ with increasing depth). Half hourly meteorological data (see Sect. 2.3) were used to force the model, these include the soil water content (which defines the volumetric size of each reservoir and the fraction of the total reactive mineral surface that is available for weathering), rainfall, soil temperature and inputs of $\mathrm{CO}_{2}$ from biological production. The latter was estimated by means of a $Q_{10}$ function $\left(Q_{10}\right.$ was 2.2 and basal rate respiration was $0.5 \mu \mathrm{mol} \mathrm{m}^{-2} \mathrm{~s}^{-1}$ ), combined with an adjustment factor for drought.We used nighttime $\mathrm{CO}_{2}$ fluxes from eddy covariance measurements during biologically active periods when geochemical fluxes were negligible. This production was prescribed only in the two upper layers (soil) and was assumed to be zero during the drought period, during which all plants are senescent and $\mathrm{CO}_{2}$ efflux was typically zero in the absence of high turbulence. The measured daytime effluxes in this season could therefore not be attributed to respiration, making this the appropriate period to study ventilation. In order to reproduce the observed $\mathrm{CO}_{2}$ concentrations in both the upper and deeper layers, we encountered the need to also include very little $\left(0.1 \mu \mathrm{mol} \mathrm{m}{ }^{-2} \mathrm{~s}^{-1}\right)$ but continuous $\mathrm{CO}_{2}$ production in one of the deeper layers in the model. Possible sources of this deep $\mathrm{CO}_{2}$ production in the karst system are treated in the discussion below.

\subsection{Measurements}

In 2009, the fluxes of $\mathrm{CO}_{2}$ and $\mathrm{H}_{2} \mathrm{O}$ were estimated from $10 \mathrm{~Hz}$ eddy covariance measurements at $2.5 \mathrm{~m}$ height. The extent of fetch, i.e., the distance upwind over the homogeneous surface, is several hundreds of meters from the tower in every direction. An open-path infrared gas an- alyzer (Li-Cor 7500, Lincoln, NE, USA) measured densities of $\mathrm{CO}_{2}$ and $\mathrm{H}_{2} \mathrm{O}$; it was calibrated monthly using an $\mathrm{N}_{2}$ standard for zero and a $500.1 \mu \mathrm{mol}\left(\mathrm{CO}_{2}\right) \mathrm{mol}^{-1}$ gas standard as a span. Wind speed and sonic temperature were measured by a three-axis sonic anemometer (CSAT-3, Campbell Scientific, Logan, UT, USA).

A thermohygrometer (HMP 35C, CSI, USA) at $1.5 \mathrm{~m}$ above the surface was used to measure air temperature and humidity. Soil water content (SWC) was measured by three water content reflectometers (CS615, CSI) at $4 \mathrm{~cm}$ depth. Soil temperature was determined as the mean of two pairs of thermocouples (TCAV, CSI) at $2 \mathrm{~cm}$ and $6 \mathrm{~cm}$. Rainfall was measured by a tipping bucket $(0.2 \mathrm{~mm})$ rain gauge (model 785 M, Davis Instruments Corp., Hayward, CA, USA). Fluxes of incident and reflected photons in photosynthetic wavelengths, measured by two quantum sensors (Li190, Li-Cor, Lincoln, NE, USA) at $1.5 \mathrm{~m}$ over a representative ground surface were used to determine $F_{\mathrm{p}}$ (photosynthetically active photon flux density).

The measurement system centers on a datalogger (CR3000, CSI) that calculated and stored means, variances and co-variances of $10 \mathrm{~Hz}$ data every $30 \mathrm{~min}$. Eddy fluxes calculated from density fluctuations (Webb et al., 1980) and coordinate rotations (McMillen, 1988) were carried out in post-processing. Measurements of nighttime $\mathrm{CO}_{2}$ fluxes with friction velocity lower than $0.2 \mathrm{~m} \mathrm{~s}^{-1}$ were eliminated from the analysis to avoid possible underestimation due to low turbulence (Serrano-Ortiz et al., 2009); for further details see Serrano-Ortiz et al. (2009).

Deep $\mathrm{CO}_{2}$ molar fraction was measured in a borehole $(7 \mathrm{~m}$ depth and $0.1 \mathrm{~m}$ diameter) through the bedrock outcropping using a GMP-343 (Vaisala, Inc., Finland). These measurements were made every $30 \mathrm{~s}$ and stored as $5 \mathrm{~min}$ averages in a datalogger (CR23X,CSI).

\section{Results}

In order to test whether carbonate weathering processes alone (i.e., in the absence of ventilation) could be responsible for the atypical $\mathrm{CO}_{2}$ fluxes measured over carbonate soils, we applied the geochemical model WITCH (Goddéris et al., 2006) and tested it at one of the sites where non-biological $\mathrm{CO}_{2}$ flux behavior has been observed during specific periods, as shown in Fig. 1.

The diurnal pattern of calcium carbonate precipitation (positive, $\mathrm{CO}_{2}$ production) and dissolution (negative, $\mathrm{CO}_{2}$ consumption) is shown in Fig. 2 for three different scenarios using the WITCH model. The dotted line shows a typical day in the wet season (winter), when geochemical fluxes are close to zero and thus of marginal importance compared to biological fluxes. The dashed line shows a typical day in the dry season, showing that geochemical fluxes are now slightly larger than in the wet season, due to a larger relative difference in soil water content (SWC) between night and day. In 


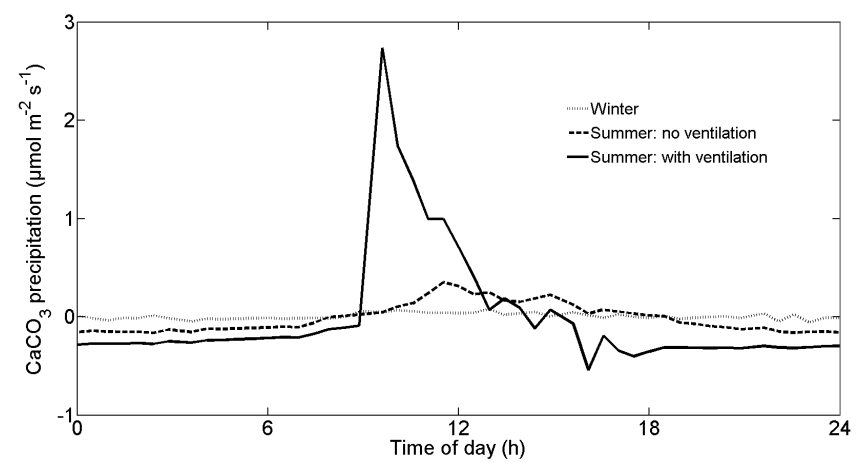

Fig. 2. Diel patterns of carbonate weathering. Figure 2 shows the diurnal pattern of calcium carbonate precipitation (positive, $\mathrm{CO}_{2}$ production) and dissolution (negative, $\mathrm{CO}_{2}$ consumption) for three different scenario's using the WITCH model. The dotted line shows a typical day in the wet season (winter), when geochemical fluxes are close to zero and thus of marginal importance compared to biological fluxes. The dashed line shows a typical day in the dry season when ventilation was not included in the model. Geochemical fluxes are now slightly larger than in the wet season, due to a larger relative difference in soil water content (SWC) between night and day. The solid line shows the same day in the dry season, but here ventilation was included in the model. Calcium carbonate precipitation and dissolution are now strongly enhanced by ventilation.

these simulations, however, soil $\mathrm{CO}_{2}$ outgassing was driven only by gas diffusion, while in reality pressure pumping and subsequent ventilation can be much more important determinants of soil gas exchange as well as soil $\mathrm{CO}_{2}$ concentrations (Takle et al., 2004). By altering soil $\mathrm{CO}_{2}$ concentrations, ventilation could be expected to affect carbonate weathering rates. To quantify this effect, we used the extended WITCH model, where ventilation was added as an alternative gas transport mechanism next to diffusion. The model with ventilation (Fig. 2, solid line), revealed much higher daytime carbonate precipitation rates as compared to the simulations without ventilation. Calcium carbonate reactions are strongly enhanced by ventilative outgassing and the peak of $\mathrm{CaCO}_{3}$ precipitation with ventilation is 8 times higher than without ventilation for the same day in the dry season.

The modeled ventilation efflux calculated using Eq. (2) is shown for two different dry periods in Fig. 3. The model was able to capture days when ventilation occurred and predicted peaks with a magnitude comparable to the observations. The main discrepancies were the modeled ventilation occurring a few hours earlier and lasting a shorter time than the observed ventilation. However, model performance was found to be sufficient for the purpose of this study, which is the evaluation of the impact of ventilation on carbonate weathering. We evaluated the role of ventilation in modifying the chemical weathering rates at annual timescale and found that our model simulated, for the site under study, a reduction in net $\mathrm{CO}_{2}$ uptake by carbonate dissolution of $16 \%$ $\left(4 \mathrm{~g} \mathrm{C} \mathrm{m}^{-2} \mathrm{yr}^{-1}\right)$. This is thus of small importance relative to the roles of biological $\mathrm{CO}_{2}$ production and climate. The associated denudation rates calculated (according to Plan, 2005) for this study site were $83 \mathrm{~mm} \mathrm{kyr}^{-1}$ for simulations without ventilation and $68 \mathrm{~mm} \mathrm{kyr}^{-1}$ for simulations with ventilation. Thus, the $16 \%$ reduction in annual carbonate dissolution induced by ventilation amounts to $15 \mathrm{~mm}$ less chemical removal of carbonate rock over a millennium.

\section{Discussion}

Model outcomes suggest that carbonate weathering rates are highly dynamical, changing in sign and magnitude on hourly, daily and seasonal timescales. During wetter periods or periods with lower turbulence when ventilation does not occur (Serrano-Ortiz et al., 2010), the contribution of the geochemical flux to the total $\mathrm{CO}_{2}$ efflux is marginal (Fig. 2, dotted line) and the $\mathrm{CO}_{2}$ fluxes associated with Eq. (1) are generally too small to explain the large $\mathrm{CO}_{2}$ fluxes presented in Fig. 1. On the other hand, when ventilation was included in the model, the peak geochemical fluxes during turbulent daytime periods in the dry season (Fig. 2, solid line) are much larger and even within the same order of magnitude as the observed atypical fluxes at this site (ranging between $0.5-6.4 \mu \mathrm{mol} \mathrm{m} \mathrm{m}^{-2} \mathrm{~s}^{-1}$ in the considered year). Carbonate geochemistry, when incited by atmospheric turbulence, can thus be an important contribution to synoptic $\mathrm{CO}_{2}$ fluxes.

One of the main factors controlling ventilation is the amount of water in the soil, as this determines the degree of connectivity in the soil-atmosphere system. The drier the soil, the larger the potential for ventilation to remove $\mathrm{CO}_{2}$ from the soil. Analysis of the flux observations in Sierra de Gádor, showed that ventilation occurs primarily during dry periods (here when soil water content $<11 \%$, but this strongly depends on the site-specific soil properties), and then only when the surface is heated. Under these conditions, ventilation-driven $\mathrm{CO}_{2}$ emissions are well correlated with evapotranspiration and the friction velocity $\mathrm{u}_{*}$ (Kowalski et al., 2008, and see also inset Fig. 1; Sanchez-Cañete et al., 2011; Serrano-Ortiz et al., 2010). At higher $\mathrm{u}_{*}$ (a proxy for atmospheric turbulence), the combination of a smaller surface boundary layer resistance and increased pressure pumping (Takle et al., 2004) enhances the export of $\mathrm{CO}_{2}$ from the subterranean air to the atmosphere. Note that higher values of atmospheric turbulence tend to be associated with higher temperatures, leading to an increased $\mathrm{CO}_{2}$ efflux at higher temperatures. This should, however, not be mistaken for the temperature dependency of respiration, given that attributing the atypical observations to biological respiration would come down to $Q_{10}$ values (the factor by which the soil respiration rate increases with a $10^{\circ}$ rise in temperature) exceeding 100, which is biologically impossible (Davidson and Janssens, 2006). During the nighttime, on the other hand, the re-humidification of the soil that is observed during dry 

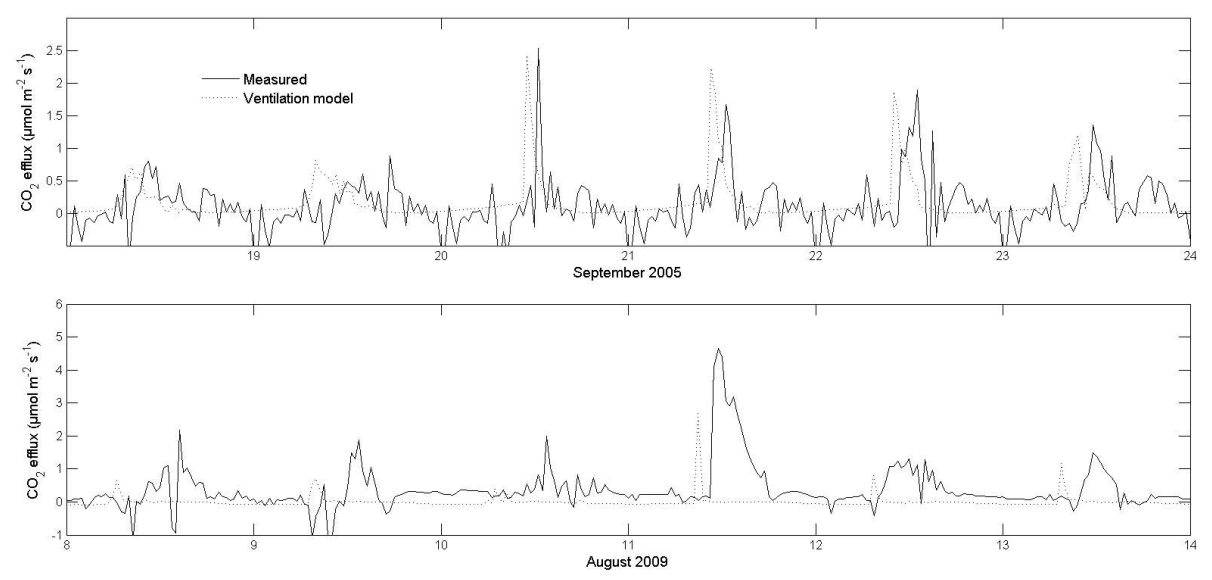

Fig. 3. Comparison of measured and modeled $\mathrm{CO}_{2}$ efflux. Comparison the the time series of the ventilative $\mathrm{CO}_{2}$ efflux as measured (black line) and modeled (dotted line). Two different periods are displayed, each of years with a very distinct dry season.

summers (due to condensation and hydraulic uplifting of water from deeper layers) (Kosmas et al., 2001; Verhoef et al., 2006), the lack of surface heating, and the lower level of air turbulence, limit the nocturnal ventilation and allow soil $\mathrm{CO}_{2}$ concentrations to rise again.

Figure 4 gives an overview of the daily cycle. During the day, ventilation lowers the gaseous subterranean $\mathrm{CO}_{2}$ concentrations, which stimulates carbonate precipitation and thus geochemical $\mathrm{CO}_{2}$ production (Eq. 1). This geochemical $\mathrm{CO}_{2}$ is in turn transported to the atmosphere by ventilation. The stronger the ventilation, the larger the reduction in soil $p \mathrm{CO}_{2}$, and the more carbonate is precipitated. Carbonate continues to precipitate as long as soil $p \mathrm{CO}_{2}$ continues to decline (Fig. 4, left).

Large daytime ventilation events bring surface soil $p \mathrm{CO}_{2}$, at the end of the day, close to atmospheric values and this very small soil-atmosphere $\mathrm{CO}_{2}$ gradient then leads to reduced diffusive $\mathrm{CO}_{2}$ outgassing during the night. Also, nocturnal rewetting of the upper soil layers (due to condensation/adsorption processes (Agam and Berliner, 2006) and hydraulic redistribution (Scott et al., 2008)) reduces the open porosity and thus limits diffusion of $\mathrm{CO}_{2}$ towards the atmosphere. This reduced diffusion, together with the lack of ventilation at night, allows soil $\mathrm{CO}_{2}$ concentrations to slowly rise again throughout the night, as a result of biological production or upward migration of $\mathrm{CO}_{2}$ from deeper soil layers. This slow but steady increase in soil $\mathrm{CO}_{2}$ concentration continuously pushes carbonate weathering reactions towards dissolution and thus $\mathrm{CO}_{2}$ consumption (Fig. 4, right). During periods of very low biological $\mathrm{CO}_{2}$ production, this can even result in net $\mathrm{CO}_{2}$ uptake by the soil at night as is occasionally observed (Fig. 1). A day with high ventilation will thus tend to be followed by a night with a large relative increase in soil $p \mathrm{CO}_{2}$ and subsequent enhanced carbonate dissolution (see Fig. 2, solid line). In other words, the more ventilation, the more pronounced the diel weathering pattern, but the effect on net daily carbonate weathering is small because of compensatory reactions during the night. Similarly, days with larger ventilation and net carbonate precipitation will be compensated by subsequent days with weak ventilation and net carbonate dissolution, constraining the net weathering rates at longer timescales. This mechanism was confirmed by our model simulations.

Note that outgassing of $\mathrm{CO}_{2}$ through turbulence-induced pressure pumping also occurs on non-carbonate ecosystems, but in that case acts only on the gas transport from the uppermost soil layer and not on the production of $\mathrm{CO}_{2}$ (Subke et al., 2003). In carbonate ecosystems, removal of $\mathrm{CO}_{2}$ via turbulence-driven mass transport does affect its production by stimulating carbonate precipitation.

Uncertainty exists concerning the processes responsible for the replenishment of subterranean $\mathrm{CO}_{2}$ levels at night, crucial for allowing ventilation to occur again the next day. As stated before, at the end of a well-ventilated day, the $p \mathrm{CO}_{2}$ in the uppermost soil layers is not much higher than atmospheric values. This very low surface soil $p \mathrm{CO}_{2}$ enhances upward $\mathrm{CO}_{2}$ diffusion from pores and cavities in the bedrock deeper below. However, this would deplete the $\mathrm{CO}_{2}$ reserves in these deeper layers, which is not observed in the field. Also, the observed $\mathrm{CO}_{2}$ concentrations in both the upper and deeper layers could only be simulated well with our model by including a very small $\left(0.1 \mu \mathrm{mol} \mathrm{m}{ }^{-2} \mathrm{~s}^{-1}\right)$ but continuous production of $\mathrm{CO}_{2}$ in the deeper layers. Possible sources of this upward $\mathrm{CO}_{2}$ migration from deep below, include microbial decomposition of dissolved organic carbon (DOC), calcite precipitation in deeper layers, or geotectonic activity. Very high $\mathrm{CO}_{2}$ concentrations in cavities deep in the bedrock have indeed been measured at this site $(>15000 \mathrm{ppm}$ at $-7 \mathrm{~m}$; Sanchez-Cañete et al., 2011) and other karst sites in the surrounding area, and many field studies support our assumption of an additional deep $\mathrm{CO}_{2}$ source originating at or immediately above the water table (Benavente et al., 2010; 


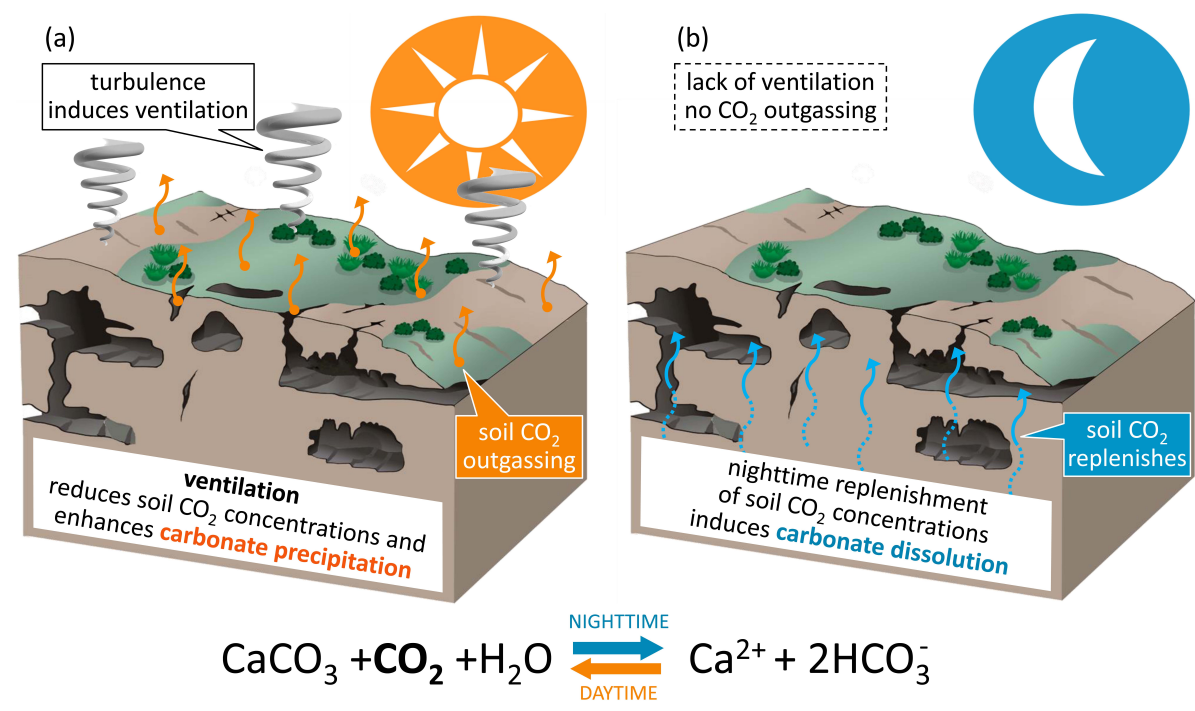

Fig. 4. Overview of the diurnal cycle of carbonate geochemistry with ventilation. Figure 4 shows a conceptual framework that may explain why and how diurnal cycle of carbonate dissolution and precipitation can be exacerbated by ventilation.

(a) During the day, gaseous subterranean $\mathrm{CO}_{2}$ concentrations are kept low by ventilation, which stimulates carbonate precipitation and concurrent geochemical $\mathrm{CO}_{2}$ production. This $\mathrm{CO}_{2}$ is then again removed by ventilation, thus sustaining prolonged $\mathrm{CO}_{2}$ emission events even in the absence of respiratory $\mathrm{CO}_{2}$ production. The stronger the ventilation, the more carbonate precipitates.

(b) At night, ventilation ceases and diffusion of $\mathrm{CO}_{2}$ from the soil to the atmosphere is reduced by: first, nocturnal rewetting of the upper soil layer that reduces open porosity and, second, the small $\mathrm{CO}_{2}$ concentration difference between soil and atmosphere resulting from a day with ventilation. $\mathrm{CO}_{2}$ from deeper layers migrates upwards to the depleted upper layers, where it stimulates carbonate dissolution and thus $\mathrm{CO}_{2}$ consumption.

Linan et al., 2008; Walvoord et al., 2005; Wood et al., 1993). Both biotic and abiotic processes have been demonstrated as sources of $\mathrm{CO}_{2}$ in studies conducted in the proximity of the considered study site: (a) geotectonic mantle-derived $\mathrm{CO}_{2}$ migrating upward from deeper parts of the crust through regional faults and seismic activity (Ceron et al., 1998), (b) microbial decomposition of dissolved and solid organic carbon near the groundwater table (typically hundreds of meters deep) (Benavente et al., 2010) and (c) $\mathrm{CO}_{2}$ from local calcite precipitation near the groundwater table (Benavente et al., 2010). The exact origin of the $\mathrm{CO}_{2}$ production that we prescribed at this study site remains uncertain.

At most sites and during most of the year, biological fluxes are much larger than geochemical $\mathrm{CO}_{2}$ production or consumption, and therefore mask their contribution to the ecosystem $\mathrm{CO}_{2}$ exchange with the atmosphere. However, our results show that in some regions carbonate weathering rates are not negligible relative to biological fluxes during dry (low biological activity and system prone to ventilation) and windy periods. Under such conditions, biology-based standardized schemes to partition the measured net $\mathrm{CO}_{2}$ exchange into its components - as are used by the FLUXNET (Baldocchi et al., 2001) community - are not applicable and gas exchange measurements fail to reveal any information on the biological activity at these sites (Were et al., 2010). Quantification of the short-term and annual contribution of carbonate weathering rates to the measured ecosystem-atmosphere
$\mathrm{CO}_{2}$ exchange can now be achieved by coupling the modified WITCH model to existing soil vegetation atmosphere transfer (SVAT) models. Given that carbonate systems cover more than $10 \%$ of the world's land surface (Durr et al., 2005) and most of these occur in relatively dry regions, a potential contribution of carbonate weathering to the short-term $\mathrm{CO}_{2}$ flux measurements should not a priori be discarded. The $15 \mathrm{~mm} \mathrm{kyr}^{-1}$ reduction in denudation rates due to ventilation is small relative to erosion, but may not be trivial on longer timescales.

\section{Supplementary material related to this article is available online at: http://www.biogeosciences.net/10/ 5009/2013/bg-10-5009-2013-supplement.pdf.}

Acknowledgements. M. Roland was granted by the Institute for Promotion of Innovation through Science and Technology in Flanders (IWT-Vlaanderen). I. A. Janssens and R. Van Grieken acknowledge the Research Foundation - Flanders (FWO). P. Serrano-Ortiz is funded by a postdoctoral fellowship from the Spanish Ministry of Science and Innovation. S. Cuezva was funded by a postdoctoral fellowship from the Spanish Ministry of Science and Innovation, research programme Juan de la Cierva.

Edited by: F. X. Meixner 


\section{References}

Agam, N. and Berliner, P. R.: Dew formation and water vapor adsorption in semi-arid environments - A review, J. Arid Environ., 65, 572-590, doi:10.1016/j.jaridenv.2005.09.004, 2006.

Baldocchi, D., Falge, E., Gu, L. H., Olson, R., Hollinger, D., Running, S., Anthoni, P., Bernhofer, C., Davis, K., Evans, R., Fuentes, J., Goldstein, A., Katul, G., Law, B., Lee, X. H., Malhi, Y., Meyers, T., Munger, W., Oechel, W., Paw, K. T., Pilegaard, K., Schmid, H. P., Valentini, R., Verma, S., Vesala, T., Wilson, K., and Wofsy, S.: FLUXNET: A new tool to study the temporal and spatial variability of ecosystem-scale carbon dioxide, water vapor, and energy flux densities, B. Am. Meteorol. Soc., 82, 2415-2434, 2001.

Benavente, J., Vadillo, I., Carrasco, F., Soler, A., Linan, C., and Moral, F.: Air Carbon Dioxide Contents in the Vadose Zone of a Mediterranean Karst, Vadose Zone J., 9, 126-136, doi:10.2136/vzj2009.0027, 2010.

Berner, R. A., Lasaga, A. C., and Garrels, R. M.: The CarbonateSilicate Geochemical Cycle and its Effect on Atmospheric Carbon-Dioxide over the past hundred Million Years, Am. J. Sci., 283, 641-683, 1983.

Ceron, J. C., Pulido-Bosch, A., and Sanz de Galdeano, C.: Isotopic identification of $\mathrm{CO}_{2}$ from a deep origin in thermomineral waters of southeastern Spain, Chem. Geol., 149, 251-258, 1998.

Cuezva, S., Fernandez-Cortes, A., Benavente, D., Serrano-Ortiz, R., Kowalski, A. S., and Sanchez-Moral, S.: Short-term $\mathrm{CO}_{2}(\mathrm{~g})$ exchange between a shallow karstic cavity and the external atmosphere during summer: Role of the surface soil layer, Atmos. Environ., 45, 1418-1427, doi:10.1016/j.atmosenv.2010.12.023, 2011.

Davidson, E. A. and Janssens, I. A.: Temperature sensitivity of soil carbon decomposition and feedbacks to climate change, Nature, 440, 165-173, 2006.

Dreybrodt, W., Lauckner, J., Liu, Z. H., Svensson, U., and Buhmann, D.: The kinetics of the reaction $\mathrm{CO}_{2}+\mathrm{H}_{2} \mathrm{O}->\mathrm{H}++\mathrm{HCO}_{3}$ - as one of the rate limiting steps for the dissolution of calcite in the system $\mathrm{H}_{2} \mathrm{O}-\mathrm{CO}_{2}-\mathrm{CaCO}_{3}$, Geochim. Cosmochim. Ac., 60, 3375-3381, 1996.

Durr, H. H., Meybeck, M., and Durr, S. H.: Lithologic composition of the Earth's continental surfaces derived from a new digital map emphasizing riverine material transfer, Global Biogeochem. Cy., 19, Gb4s10 doi:10.1029/2005gb002515, 2005.

Emmerich, W. E.: Carbon dioxide fluxes in a semiarid environment with high carbonate soils, Agr. Forest Meteorol., 116, 91-102, 2003.

Eshel, G., Fine, P., and Singer, M. J.: Total soil carbon and water quality: An implication for carbon sequestration, Soil Sci. Soc. Am. J., 71, 397-405, doi:10.2136/sssaj2006.0061, 2007.

Goddéris, Y., Francois, L. M., Probst, A., Schott, J., Moncoulon, D., Labat, D., and Viville, D.: Modelling weathering processes at the catchment scale: The WITCH numerical model, Geochim. Cosmochim. Ac., 70, 1128-1147, doi:10.1016/j.gca.2005.11.018, 2006.

Goddéris, Y., Williams, J. Z., Schott, J., Pollard, D., and Brantley, S. L.: Time evolution of the mineralogical composition of the Mississippi Valley loess over the last $10 \mathrm{kyr}$ : climate and geochemical modeling, Geochim. Cosmochim. Ac., 74, 6357-6374, 2010 .
Hastings, S. J., Oechel, W. C., and Muhlia-Melo, A.: Diurnal, seasonal and annual variation in the net ecosystem $\mathrm{CO}_{2}$ exchange of a desert shrub community (Sarcocaulescent) in Baja California, Mexico, Glob. Change Biol., 11, 927-939, doi:10.1111/j.13652486.2005.00951.x, 2005.

Kaufmann, G. and Dreybrodt, W.: Calcite dissolution kinetics in the system $\mathrm{CaCO}_{3}-\mathrm{H}_{2} \mathrm{O}-\mathrm{CO}_{2}$ at high undersaturation, Geochim. Cosmochim. Ac., 71, 1398-1410, doi:10.1016/j.gca.2006.10.024, 2007.

Kosmas, C., Marathianou, M., Gerontidis, S., Detsis, V., Tsara, M., and Poesen, J.: Parameters affecting water vapor adsorption by the soil under semi-arid climatic conditions, Agr. Water Manage., 48, 61-78, 2001.

Kowalski, A. S., Serrano-Ortiz, P., Janssens, I. A., Sanchez-Moral, S., Cuezva, S., Domingo, F., Were, A., and Alados-Arboledas, L.: Can flux tower research neglect geochemical $\mathrm{CO}_{2}$ exchange?, Agr. Forest Meteorol., 148, 1045-1054, 2008.

Li, X. Y., Contreras, S., and Sole-Benet, A.: Spatial distribution of rock fragments in dolines: A case study in a semiarid Mediterranean mountain-range (Sierra de Gador, SE Spain), Catena, 70, 366-374, doi:10.1016/j.catena.2006.11.003, 2007.

Li, X. Y., Contreras, S., and Sole-Benet, A.: Unsaturated hydraulic conductivity in limestone dolines: Influence of vegetation and rock fragments, Geoderma, 145, 288-294, doi:10.1016/j.geoderma.2008.03.018, 2008.

Linan, C., Vadillo, I., and Carrasco, F.: Carbon dioxide concentration in air within the Nerja Cave (Malaga, Andalusia, Spain), Int. J. Speleol., 37, 99-106, 2008.

Massman, W., Sommerfeld, R., Zeller, K., Hehn, T., Hudnell, L., and Rochelle, S.: $\mathrm{CO}_{2}$ flux through a Wyoming seasonal snowpack: Diffusional and pressure pumping effects, International Symposium on Biogeochemistry of Seasonally Snow-Covered Catchments, at the XXI Assembly of the International-Union-of-Geodesy-and-Geophysics, Boulder, Co, ISI:A1995BF19G00009, 71-79, 1995.

McMillen, R. T.: An eddy-correlation technique with extended applicability to non-simple terrain, Bound.-Lay. Meteorol., 43, 231-245, 1988.

Mielnick, P., Dugas, W. A., Mitchell, K., and Havstad, K.: Longterm measurements of $\mathrm{CO}_{2}$ flux and evapotranspiration in a Chihuahuan desert grassland, J. Arid Environ., 60, 423-436, doi:10.1016/j.jaridenv.2004.06.001, 2005.

Plan, L.: Factors controlling carbonate dissolution rates quantified in a field test in the Austrian alps, Geomorphology, 68, 201-212, doi:10.1016/j.geomorph.2004.11.014, 2005.

Rey, A., Belelli-Marchesini, L., Were, A., Serrano-Ortiz, P., Etiope, G., Papale, D., Domingo, F., and Pegoraro, E.: Wind as a main driver of the net ecosystem carbon balance of a semiarid Mediterranean steppe in the South East of Spain, Glob. Change Biol., 18, 539-554, doi:10.1111/j.1365-2486.2011.02534.x, 2012.

Roelandt, C., Godderis, Y., Bonnet, M. P., and Sondag, F.: Coupled modeling of biospheric and chemical weathering processes at the continental scale, Global Biogeochem. Cy., 24, Gb2004, doi:10.1029/2008gb003420, 2010.

Sanchez-Cañete, E. P., Serrano-Ortiz, P., Kowalski, A. S., Oyonarte, C., and Domingo, F.: Subterranean $\mathrm{CO}_{2}$ ventilation and its role in the net ecosystem carbon balance of a karstic shrubland, Geophys. Res. Lett., 38, L09802, doi:10.1029/2011GL047077, 2011. 
Schlesinger, W. H., Belnap, J., and Marion, G.: On carbon sequestration in desert ecosystems, Glob. Change Biol., 15, 1488-1490, doi:10.1111/j.1365-2486.2008.01763.x, 2009.

Scott, R. L., Cable, W. L., and Hultine, K. R.: The ecohydrologic significance of hydraulic redistribution in a semiarid savanna, Water Resour. Res., 44, W02440, doi:10.1029/2007wr006149, 2008.

Serrano-Ortiz, P., Kowalski, A. S., Domingo, F., Rey, A., Pegoraro, E., Villagarcia, L., and Alados-Arboledas, L.: Variations in daytime net carbon and water exchange in a montane shrubland ecosystem in southeast Spain, Photosynthetica, 45, 30-35, 2007.

Serrano-Ortiz, P., Domingo, F., Cazorla, A., Were, A., Cuezva, S., Villagarcia, L., Alados-Arboledas, L., and Kowalski, A. S.: Interannual $\mathrm{CO}_{2}$ exchange of a sparse Mediterranean shrubland on a carbonaceous substrate, J. Geophys. Res.-Biogeosci., 114, G04015, doi:10.1029/2009jg000983, 2009.

Serrano-Ortiz, P., Roland, M., Sanchez-Moral, S., Janssens, I. A., Domingo, F., Goddéris, Y., and Kowalski, A. S.: Hidden, abiotic $\mathrm{CO}_{2}$ flows and gaseous reservoirs in the terrestrial carbon cycle: Review and perspectives, Agr. Forest Meteorol., 150, 321-329, 2010.

Subke, J. A., Reichstein, M., and Tenhunen, J. D.: Explaining temporal variation in soil $\mathrm{CO}_{2}$ efflux in a mature spruce forest in Southern Germany, Soil Biol. Biochem., 35, 1467-1483, doi:10.1016/s0038-0717(03)00241-4, 2003.

Suchet, P. A. and Probst, J. L.: A global-model for present-day atmospheric soil $\mathrm{CO}_{2}$ consumption by chemical erosion of continental rocks $\left(\mathrm{GEM}-\mathrm{CO}_{2}\right)$, Tellus B, 47, 273-280, 1995.

Takle, E. S., Brandle, J. R., Schmidt, R. A., Garcia, R., Litvina, I. V., Massman, W. J., Zhou, X. H., Doyle, G., and Rice, C. W.: High-frequency pressure variations in the vicinity of a surface $\mathrm{CO}_{2}$ flux chamber, Agr. Forest Meteorol., 114, 245-250, 2003.
Takle, E. S., Massman, W. J., Brandle, J. R., Schmidt, R. A., Zhou, X. H., Litvina, I. V., Garcia, R., Doyle, G., and Rice, C. W.: Influence of high-frequency ambient pressure pumping on carbon dioxide efflux from soil, Agr. Forest Meteorol., 124, 193-206, doi:10.1016/j.agrformet.2004.01.014, 2004.

Verhoef, A., Diaz-Espejo, A., Knight, J. R., Villagarcia, L., and Fernandez, J. E.: Adsorption of water vapor by bare soil in an olive grove in southern Spain, J. Hydrometeorol., 7, 1011-1027, 2006.

Walvoord, M. A., Striegl, R. G., Prudic, D. E., and Stonestrom, D. A.: $\mathrm{CO}_{2}$ dynamics in the Amargosa Desert: Fluxes and isotopic speciation in a deep unsaturated zone, Water Resour. Res., 41, W02006, doi:10.1029/2004wr003599, 2005.

Webb, E. K., Pearman, G. I., and Leuning, R.: Correction of flux measurements for density effects due to heat and water-vapor transfer, Q. J. Roy. Meteor. Soc., 106, 85-100, 1980.

Were, A., Serrano-Ortiz, P., Moreno de Jong, C., Villagarcía, L., Domingo, F., and Kowalski, A. S.: Ventilation of subterranean $\mathrm{CO}_{2}$ and Eddy covariance incongruities over carbonate ecosystems, Biogeosciences, 7, 859-867, doi:10.5194/bg-7-859-2010, 2010.

Wohlfahrt, G., Fenstermaker, L. F., and Arnone, J. A.: Large annual net ecosystem $\mathrm{CO}_{2}$ uptake of a Mojave Desert ecosystem, Glob. Change Biol., 14, 1475-1487, doi:10.1111/j.13652486.2008.01593.x, 2008.

Wood, B. D., Keller, C. K., and Johnstone, D. L.: In situ measurement of microbial activity and controls on microbial $\mathrm{CO}_{2}$ production in the unsaturated zone, Water Resour. Res., 29, 647659, 1993.

Xie, J. X., Li, Y., Zhai, C. X., Li, C. H., and Lan, Z. D.: CO 2 absorption by alkaline soils and its implication to the global carbon cycle, Environ. Geol., 56, 953-961, doi:10.1007/s00254-008-1197$0,2009$. 